\title{
Assessing destination images of an Olympic host city using social media
}

\author{
Maria Banyai $^{1 *}$ and Luke R. Potwarka ${ }^{2}$ \\ Received: 09/03/2011 Accepted: 07/08/2011
}

\begin{abstract}
${ }^{1}$ School of Hospitality and Tourism Management, Centre for Hospitality and Culinary Arts, George Brown College, 300 Adelaide Street East, Toronto, Ontario, Canada M5T 2T9, phone: 1-416-450-5000, ext. 3303, e-mail: mbanyai@georgebrown.ca

2 Department of Recreation and Leisure Studies, University of Waterloo, 200 University Avenue West, Waterloo, Ontario, Canada N2L 3G1; phone: 1-519- 888-4567, ext. 33894, e-mail: Irpotwarka@uwaterloo.ca

* Corresponding author
\end{abstract}

\section{Abstract}

The purpose of this study was to assess destination image components of Vancouver post 2010 Olympic Winter Games. To fulfill this aim, the present investigation examined comments posted on Tourism Vancouver's official Facebook website. An analysis of the Facebook posts using CATPAC II software revealed two clusters of image components related to Vancouver. The findings suggest that the 2010 Vancouver Winter Olympics may not have had a substantial impact on the overall images people held of the city, or in terms of their intention to revisit the destination. We advance the position that staging a sport mega-event, by itself, will not influence destination image unless effective marketing strategies are adopted.

(c) 2012 International University College. All rights reserved

Keywords: destination image, Olympic tourism, social media, intentions to revisit, CATPAC II

Citation: Banyai, M., L. Potwarka (2012) Assessing destination images of an Olympic host city using social media. European Journal of Tourism Research 5(1), pp. 6-18

\section{Introduction}

The commitment of public money to host mega-events such as the Olympic Games is often justified by the assumption that such an event will improve the local economy via increased tourism (Crompton \& Lee, 2000). Consequently, politicians and researchers are concerned with the degree to which staging a mega-sport event can enhance the destination image of a host region, and subsequently, stimulate post-event domestic and international travel behaviour (Chalip, Green, \& Hill, 2003; Kaplandiou, 2007; Kaplanidou \& Gibson, 2010; Gibson, Qi, \& Zhang, 2008). Gibson et al. (2008) noted that with the strategic leveraging of images that are shown to the world in conjunction with the event (pre, during, and after),"the level of awareness of a particular city and/or country can be raised, which may in turn provide the impetus to visit at some point in the future, or at the very least be used to educate the world about a particular locale" (p. 446). 
Thus, the purpose of this study was to assess destination image components of Vancouver post 2010 Olympic Winter Games. To fulfill this aim, the present investigation examined comments posted on Tourism Vancouver's official Facebook website. Tourism researchers have suggested that these types of online social networking mediums (e.g., travel blogs, posts, comments) are a "promising way to assess the image of a destination among a particular traveler group which is otherwise hard to reach" (Schmallegger \& Carson, 2008, p. 105). Indeed, there have been calls in the literature for a movement beyond traditional marketing research techniques (e.g., surveys, focus groups, interviews) aimed at gathering tourist data related to destination image and intentions to revisit (Pan, MacLaurin, \& Crotts, 2007). By utilizing online social networking mediums, Olympic host cities may gain valuable information about tourists' perceived images of the destination and make necessary adjustments in their marketing strategies to ensure the likelihood of revisits. Currently, Facebook is actively supporting more than 800 million users, with people spending over 800 billion minutes every month socializing. The network has penetrated the global social sphere, with more than 70 translations, and about $80 \%$ of users being outside the United States (Facebook, 2012).

With some exceptions (e.g., Kaplanidou, 2007; Kaplanidou \& Vogt, 2009), there has been a relative paucity of research examining the influence of hosting the Olympics on destination image formation. Moreover, the extent to which online social networking sites can provide meaningful information about the image of a destination is garnering greater attention from tourism researchers (Carson, 2008; Choi, Lehto \& Morrison, 2007; Pan, MacLaurin, \& Crotts, 2007; Wenger, 2008). Previous studies (e.g., Kaplanidou 2007; Kaplanidou \& Vogt, 2009) examining destination images of host Olympic cities have relied on traditional quantitative approaches to eliciting image-related information (i.e., surveys using standardized scaling procedures). However, mediums such as Facebook may provide more unbiased accounts of the destination images people hold in relation to a host city in the wake of the Olympic Games. In other words, online social networking sites allow researchers to elicit information regarding destination images in a "real time" and "real world" setting. To date, no previous study has investigated an Olympic host city destination images as portrayed on Facebook.

\section{Review of Related Literature}

\section{Destination Image and Mega Sport Events}

Destination image has been the research topic of over 142 articles published in international journals and conference proceedings since 1973 (Pike, 2002). Destination image is generally defined as the sum of impressions and perceptions tourists hold about a destination, encompassing beliefs and ideas which are selected from a variety sources of information, elaborated and embellished in the mind of travellers in order to create meanings (Baloglu \&McCleary, 1999; Echtner \& Ritchie, 1991; San Martin \& del Bosque, 2008; Tasci \& Gartner, 2007). Gartner (1993) compiled a list of eight image formation agents ranging from traditional forms of advertising (overt induced), to independent reports (autonomous), and information gathered from family and friends (solicited organic). These agents differ by the degree of control by destination marketers, the level of market penetration and the credibility they invoke in consumers (Tasci \& Gartner, 2007).

Various destination image frameworks have been proposed by researchers. Tourists' impressions and perceptions of the destination, and therefore their expectations of what they would find at the place, are based on personal characteristics and social environment, but also on stimulus factors such as information sources (Baloglu \& McCleary, 1999a). While traditional destination image research focused on the cognitive dimension, earlier studies join the cognitive and affective dimensions to capture the image of tourism destinations (Baloglu \& McCleary, 2008; San Martin \& del Bosque, 2008). The cognitive component refers to beliefs and knowledge of the tourism destination, while the affective component is represented by the emotions toward the destination. Thus, "an overall image of a place is formed as a result of both perceptual/cognitive and affective evaluations of that place" (Baloglu \& McCleary, 2008, p. 870). 
The multidimensionality of the destination image formation process was addressed by Echtner and Ritchie (1991). Their framework is based on three different sets of components: attribute-holistic (perceptions of individual attributes and holistic impressions of place), functional-psychological (observable elements and less tangible characteristics), and common-unique set (common elements and more unique specific to a destination). Although their model appears to divide the concept of image in three different and independent components, there is overlap amongst the three. As such, functional attributes could be "cool climate" and "poor nightlife", functional holistic could be perceptions of physical characteristics such as "mountainous" destination, psychological attributes would be impressions of the tangible characteristics such as "friendly people", and psychological holistic image components represent the overall impressions of the atmosphere such as "mystic" (Echtner \& Ritchie, 1991).

However, Govers, Go and Kumar (2007) argued that previous frameworks are static in nature, concentrating mostly on relationships between the destination image and a variety of agents. Their framework is aimed at identifying the actual elements that have a dynamic role in the formation of destination images. Their 3Gap Tourism Destination Image Formation Model is based on the deconstruction of the image formation process and the inclusion of several agents, such as the local tourism industry and the marketing mix used to promote the destination. By addressing specific gaps in the image formation process, destination marketers can balance the promotion of the destination with tourists' expectations and demands.

Generally, destination image research has focused on the influence of destination images on tourists' behaviour, especially as related to decision-making (Alcaniz, Garcia \& Blas, 2009; Chen \& Tsai, 2007), on the various dimensions of destination image, and on the destination image formation process along with the agents involved in the creation of images (Baloglu \& McCleary, 1999, Echtner \& Ritchie, 1991; Echtner \& Ritchie, 1993; Gartner, 1993; Govers, Go \& Kumar, 2007; Tasci \& Gartner,
2007; Tasci, Gartner, \& Cavusgil, 2007). More recently, researchers have turned their attention to the information posted online by tourists as an important source for providing an insight into perceived images of a destination. Researchers argue that the growth of travel blogging sites, such as Travelblog.org and Travelpost.com, facilitates powerful discussions impacting consumers' decision making, affecting destination images and even reshaping the communication networks previously dominated by traditional information suppliers (Wenger, 2008; Xiang \& Gretzel, 2010). The information posted online by tourists can provide valuable tools needed for various marketing strategies such as improving and monitoring destination images and products by responding to tourists' demands and expectations, and also adjusting competitive strategies (Banyai, in press; Carson, 2008; Litvin, et al., 2008, Pan et al., 2007; Wenger, 2008).

Thus far, destination image research online has focused on identifying positive and negative perceptions of a destination mainly on travel blogs (Carson, 2008; Wenger, 2008; Pan, et al., 2007), but also on other online websites such as tour operators, travel agencies and official tourism websites (Choi, Lehto \& Morrison, 2007). Researchers have found that positive and negative comments left by tourists on social network discussion boards, and the overall destination image of travellers have an important effect on behavioural intentions such as intentions to revisit and willingness to recommend (Alcaniz, Garcia \& Blas, 2009; Diaz-Marting, Iglesias, Vazquez \& Ruiz, 2000; Litvin, Blose \& Laird, 2004; Morgan, Pritchard \& Piggott, 2003; O’Neill, Palmer\& Charter, 2002).

Hall (1989a) argued that because mega events' primary function is to provide the host city with the opportunity to secure a distinctive place as a tourism destination, they can aid in the formation of tourism destination images. Similarly, Dimanche (2003) noted that hosting sporting events can have marketing implications for host cities, creating awareness of the destination, improving visitors' image, and influencing inbound travel to the destination. In a longitudinal study on awareness levels of Calgary pre and post the 
1988 Winter Olympic Games done by Ritchie and Smith (1991), it was found that international tourists' impressions and perceptions of Canada ranged from "cold", "French", "mountains", "beautiful" and "snow" within the U.S participants, while participants from Europe thought of Canada in terms of its beautiful nature and its size. Overall, the findings showed that "the hosting of the 1988 Olympic Winter Games had a dramatic impact on levels of awareness and knowledge of the city of Calgary in Europe and the United States..." (p. 8). It was found that the Olympics "totally dominated the city's image" (p. 7), being mentioned by $77 \%$ of the study participants. Similarly, Kim and Morrison's (2005) study on changes in the image of Korea after the 2002 World Cup, revealed that "the 2002 World Cup effectively contributed to enhancing the image of Korea as an attractive tourism destination" (p. 245). Also, Gibson's et al. (2008) research on the destination image and intent to visit China as a tourism destination and the host city of the 2008 Olympic Games, revealed that participants felt China had the ability to host the Olympic Games and was a safe place to travel. Moreover, their study also showed that past experience with the destination might significantly affect visitors' images of the destination, and that there was a significant relationship between destination image and intent to visit.

Politicians and researchers are concerned with the degree to which staging a mega-sport event can enhance the destination image of a host region, and subsequently, stimulate postevent domestic and international travel behaviour (Chalip, Green, \& Hill, 2003; Gibson, Qi, \& Zhang, 2008; Kaplandiou, 2007). As Gibson et al. stated,

The debate over the benefits of hosting mega sports events continues to evolve with many beginning to doubt the longterm economic and tourism benefits touted by politicians and organizing committees. What we do know is that destination image is linked to intent to travel and so, with the strategic leveraging of images that are shown to the world in conjunction with the event (pre, during, and after), the level of awareness of a particular city and/or country can be raised, which may in turn provide the impetus to visit at some point in the future, or at the very least be used to educate the world about a particular locale (p. 446)

However, Kaplanidou's (2007) study revealed that the Olympic Games' "image dimensions did not influence directly intentions to return to the destination" (p. 170). The researcher noted it is probable that Olympic tourists' feelings of the experience are limited within the event's organization and services, and do not affect the image of Athens as the Olympic host city. Moreover, the study revealed Olympic travelers who hold unfavourable images of the host destination they visited (i.e., those that perceive the city to be unexciting and unpleasant) are less likely to report intentions to return to the city/region once the event has been staged. Shonk and Chelladurai (2008) also speculated that sport tourists will be less likely to return to a destination if they perceive their present experience to be of poor service quality (e.g., negative evaluations of the quality of accommodations, sporting venue, transportation access). Thus, it is undeniable that mega sport events leave an imprint into tourists' impressions and perceptions of the host city.

\section{Methodology}

Tourism Vancouver, the destination marketing organization representing the Olympic city, has more than 11 thousand followers on Facebook who post comments related to their past, current and future experiences in Vancouver. The study sample consisted of Facebook users who left comments on Tourism Vancouver's official Facebook website between March 21, 2010, and July 21,2010 . This 4-month postOlympic period was selected as the sampling frame in hopes of capturing tourists' image of Vancouver in relation to the Olympic Games. During this time, people might still be captivated by the excitement and "buzz" surrounding the Games, which might influence their impressions of the host city as a potential travel destination (Waitt, 2003). Ritchie and Smith (1991) argued that the level of top-ofmind awareness, post 1988 Calgary Winter Olympic Games "decreases measurably after a short period of time" (p. 8). The 3-4 months 
post event time period was also used by Kim and Morrison (2005) to assess the post 2002 World Cup image of Korea.

Although the website included additional information posted by fans, such as pictures and videos, only the text comments were selected for analysis. All comments were saved in a text file and input into CATPAC II for content-analysis. CATPAC produces "a series of outputs that include a two-dimensional perceptual map, word frequency counts, and category charts that demonstrate theme associations, making it possible to identify which themes are central to the construct as well as those that occupy secondary and tertiary levels (Ryan \& Cave, 2005, p. 146). Gover and Go (2005) believe that CATPAC is valuable computer software which can be used to determine patterns of similarity and central concepts by using clustering solutions. Furthermore, Ryan and Cave (2005) also note that artificial neural network analyses try to emulate human processes of meaning creation.

CATPAC has been recognized by tourism researchers as a useful computer software for identifying destination image representations over a variety of electronic media from tourism official websites and review sites, to travel blog sites (Banyai, in press; Choi, Lehto \& Morrison, 2007; Govers, Go \& Kumar, 2007; Pan, MacLaurin \& Crotts, 200; Stepchencova \& Morrison, 2006, 2008; Tang, Choi, Morrison \& Lehto, 2007). Banyai (in press) analyzed the content of travel blogs using CATPAC to identify tourists' perceptions of a quaint artsy town as compared to the destination's positioning strategy. Govers, Go and Kumar (2007) used CATPAC to measure destination images and create clusters of images of Middle East destinations as narrated over travel websites. Ryan and Cave (2005) analyzed the data from qualitative interviews to examine the images of Australian cities. Stepchenkova and Morrison $(2006,2008)$ combined CATPAC and WORDER to analyze image representations of Russia. The researchers used only the wordfrequency ranking function of CATPAC to determine the variables of interest, or key words, for subsequent analysis.

CATPAC II was time efficient compared to traditional applications of content analysis. 10
CATPAC enabled the researchers to produce a frequency table and proximity matrix for the most often used words in the comments left on Tourism Vancouver Facebook page. The proximity matrix or dendogram (Woelfel, 1998) is based on the co-occurrence between words in one unit of analysis represented by a sliding text window. CATPAC's default window size of seven words was used to analyze the Facebook comments. This is an appropriate window size given that comments left on Facebook tend to consist of short sentences. Thus, CATAPC moved a window of seven words across the text to calculate the number of times the words were found close to each other.

Moreover, the software allowed for the elimination of words not needed in the analysis, which was very useful, given that Facebook pages by default contain specific words such as: "comment", "like", "unlike"; along with the names of the month the comments were made, and the names of those leaving comments. A default file was already in place eliminating articles, prepositions and other meaningless words such as: "is", "the", "and", etc. Also, to achieve interpretable results, plurals were replaced with singulars, past tense with present tense, and phrases related to intentions to revisit Vancouver were replaced with "revisit."

Numerous runs of CATPAC II program were conducted to ensure that no meaningless words were included in the analysis. Also, when the research is exploratory in nature, it is recommended that the analysis include 40 unique words because the resulting dendogram and visual perceptual map is easier to interpret (Woelfel, 1998). To identify homogeneous groups of words, CATPAC II was used to perform Wards' clustering method which represents clusters by their central point, using the sum of squares as the distance between two objects. This method was utilized to find out which destination image components (i.e., words) are closely connected, and related to intentions to revisit.

\section{Findings}

Word frequency

Table 1 presents the top 40 most frequently used words on Tourism Vancouver's official Facebook page. While Vancouver seems to be 
Table 1. Most Frequently Used Keywords

\begin{tabular}{llll}
\hline & Total words $=3932$ & Total unique words $=40$ & \\
\hline Keyword & Frequency & Keyword & Frequency \\
\hline Vancouver & 790 & Chinese & 30 \\
Dine & 495 & Weekend & 30 \\
Love & 424 & Menus & 29 \\
Awesome & 410 & Olympic & 29 \\
Restaurant & 224 & Delicious & 28 \\
Food & 158 & Walk & 28 \\
Yum & 118 & Amazing & 27 \\
Visit & 103 & Downtown & 26 \\
Best & 94 & Kids & 26 \\
City & 90 & Visitors & 26 \\
Park & 61 & Revisit & 25 \\
Canada & 59 & Excited & 23 \\
Nice & 55 & Victoria & 23 \\
Hungry & 47 & Festival & 22 \\
Beautiful & 45 & Wonderful & 22 \\
Granville & 45 & & \\
Life & 41 & & \\
Beach & 40 & & \\
Island & 39 & & \\
Cool & 37 & & \\
Night & 35 & & \\
Dinner & 34 & & \\
BC & 32 & & \\
Summer & 32 & & \\
Bistro & 30 & & \\
\hline
\end{tabular}

the top mentioned word by fans, the findings suggest that primary destination image components are related to food experiences. This is not surprising because during the months selected for the analysis, Tourism Vancouver had placed several promotional contests related to the city's Dine Out food and wine celebration aimed at promoting local restaurants. Nevertheless, functional images emerged such "park", "beach", and "island." As well, affective images of the destination represented by general feelings such as "love", "nice", "awesome", "excited", and "wonderful" also emerged. Moreover, the most frequently used words on Facebook were also representative of the common-unique set of the destination image. Common attractions such as "festivals" and "bistro" were images used to describe Vancouver. The unique characteristics of the destination were represented by words such as "Victoria" and "Granville."
Surprisingly, the word "Olympics" was not within the top 20 most frequently used words, and "Paralympics" did not even make the list. Intentions to "revisit" Vancouver were present in the most frequently used words. As mentioned above, intentions to "visit" and "revisit" Vancouver for pleasure travel included phrases such as "come", "come back", "go", "go back", "going" and "going back."

\section{Clustering of image components}

To further understand Vancouver's destination image post-event, a cluster analysis was performed to determine which of the most frequently used words tended to be expressed together or alongside one another (e.g., within the same phrase). The words that clustered around the words "visit" and "revisit" were also analyzed using CATPAC II cluster analysis software. 
Assessing destination images of an Olympic host city using social media.

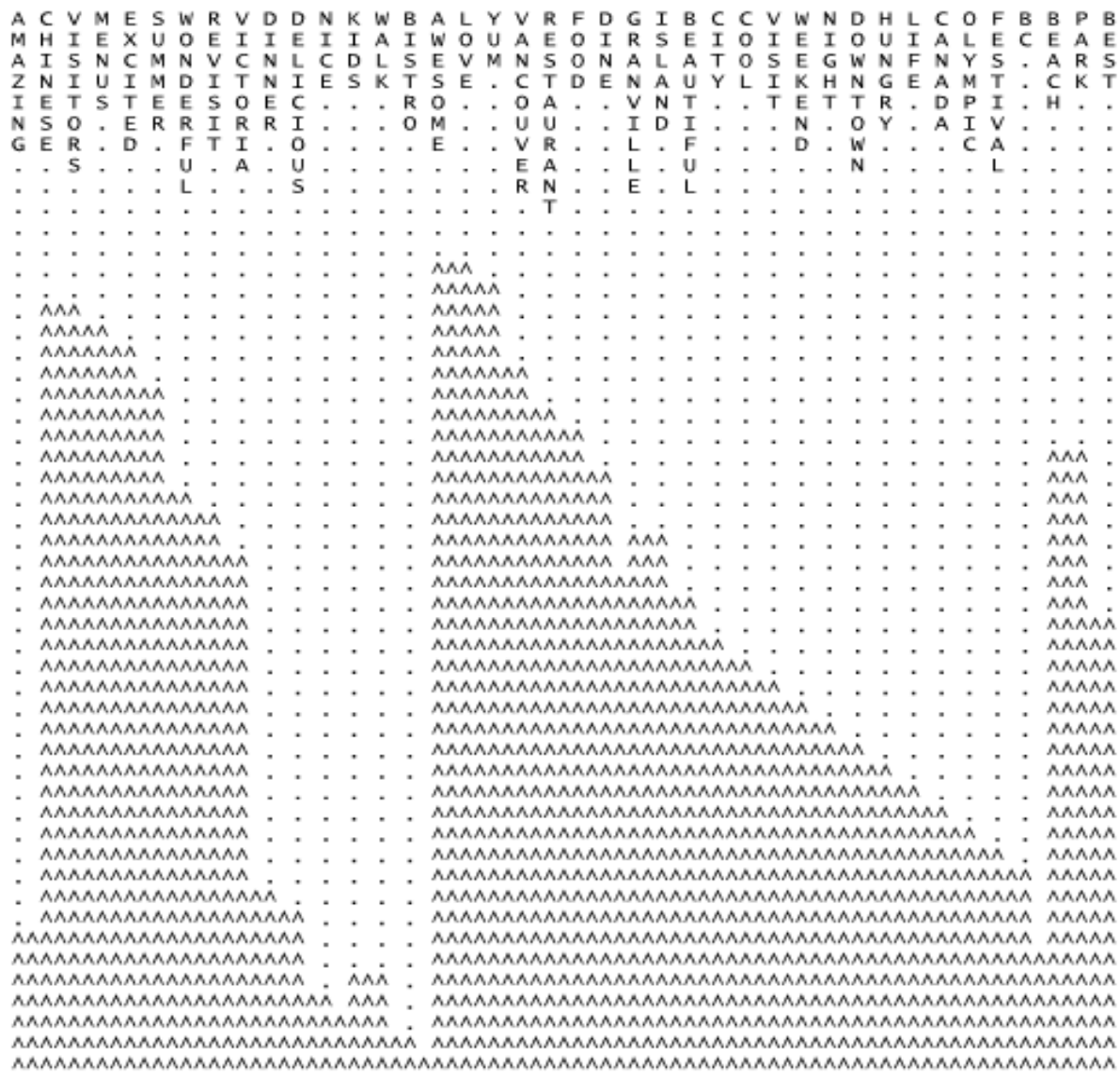

Figure 1. Wards' clustering method on Vancouver's image components

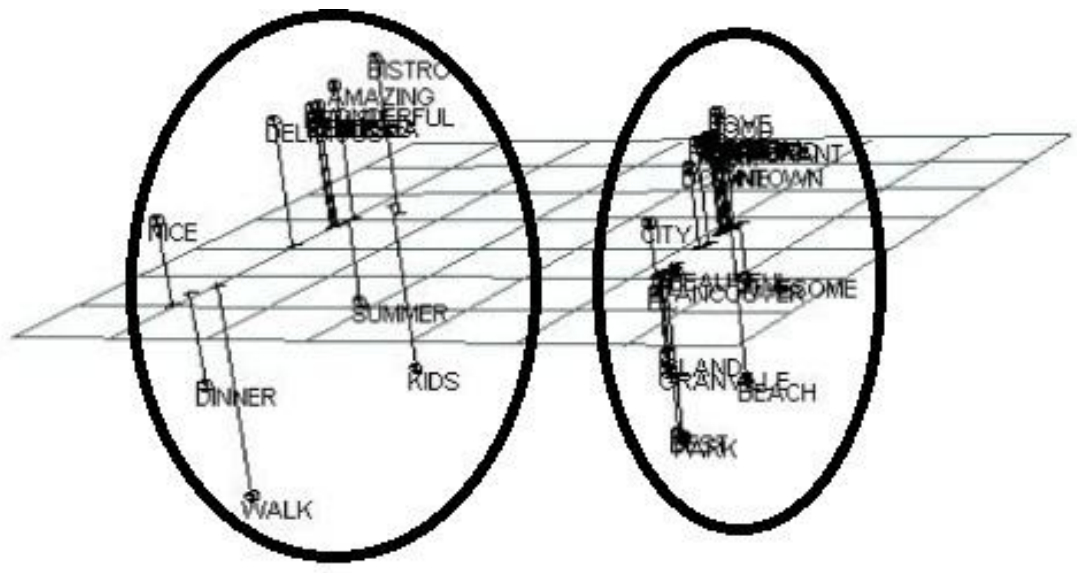

Figure 2. Perceptual Map of Image Components of Vancouver 
Based on Wards' hierarchical cluster analysis, two clusters emerged. Figure 1 illustrates the size of each cluster along with its corresponding words. The picture, called a dendogram, shows "buildings" underneath the 40 most frequently used words. The "buildings" represent the clusters, while the height illustrates how tightly the corresponding words cluster together (Woelfel, 1998). Thus, the dendogram reveals where the clusters divide and their strength. The perceptual mapping tool ThoughtView included with CATPAC II was also used to provide a three-dimensional map which visually shows which words cluster closely together, and the two main clusters that emerged (Figure 2). The left "building" in the dendogram corresponds to the left cluster circled on the perceptual map, thus the right "building" corresponds to the right circle on the perceptual map.

\section{Vancouver Image Components Cluster One}

The cluster to the left of the perceptual map (cluster one), suggests that Vancouver was described as a city popular with Chinese visitors due to the close association of the words "Chinese" and "visitors." Also, the image components "menu", "excited" and "summer", were closely related, which implies that Chinese visitors' perceptions of Vancouver included culinary images during the summer season.

Moreover, intentions to "revisit" were strongly connected to the words "wonderful" and "Victoria." Intentions to revisit were also associated with the seasonal nature of tourism, Facebook fans revealing they intend to revisit Vancouver and Victoria in the "summer." To a lesser extent, "revisit" was also connected to words such as "excited", "dinner", "delicious", "nice", "kids" and "walk."

\section{Vancouver Image Components Cluster Two}

The cluster to the right of the perceptual map (cluster two), encompasses more robust descriptors of Vancouver. The cluster includes words such as "food", "restaurant", and "yum." Vancouver was also described as an "awesome" destination, loved for its food experiences.

In addition to images of restaurants and yummy food, the cluster depicts Vancouver as a "cool" "city" with unique attractions such as the "beautiful" "Granville" "Island." Vancouver was also revealed to be a popular destination for "weekend" and "night" gateways in the "downtown" core. These image components were also associated with the Vancouver 2010 "Olympic" "festival." "Olympic" and "festival" were strongly connected with the words "Canada" and "BC" (British Columbia). The cluster also portrays Vancouver as possessing the "best" "beach(es)" and "park(s)." Finally, intentions to "visit" Vancouver were strongly connected to the words "cool" "city", "weekend", "night" and "downtown." As well, Facebook posts suggested that people intended to "visit" the "beautiful" "Granville" "Island."

\section{Discussion}

The clusters that emerged were aligned with Echtner and Ritchie's (1991) destination image formation framework. The functional and psychological image components used by the Facebook members to describe Vancouver ranged from being attribute specific to more holistic, describing a general feeling. As such, along the functional attribute holistic continuum, Vancouver is perceived to be a "cool" "city" where "Chinese" "visitors" can get a "delicious" "dinner" at "yum(my)" "restaurant(s). Also, along the psychological attribute holistic continuum, Vancouver is perceived as a "beautiful" city", a place where one can take a "nice" walk", an "amazing" and "awesome" destination. Common image components were also present in both clusters (e.g. "menus", "downtown", "beach", "park"). However, in both clusters, Vancouver was also described by participants in terms of its uniqueness as a destination: "Victoria", "Granville Island", and the "Olympic festival." Thus, in terms of the image components found, this study revealed Vancouver's destination image to be an interactive system of attributes and impressions, which is consistent with MacKay's and Fesenmaier's (1997) view that "a destination image is a composite of various products (attractions) and attributes woven into a total impression" (p. 538).

Ritchie and Smith (1991) found that the hosting of the 1988 Olympic Winter Games greatly impacted the levels of awareness of the city of Calgary. The findings of this study suggest that 
the image component "Olympics", along with other sport-related images and Paralympics, were not widely used by the Facebook members in their discussions of Vancouver post-event. This is not to say that the Olympics did not have an effect on Vancouver's destination image. Indeed, it could be that promotional ad campaigns such as the Dine Out and You Gotta Be Here had a long term impact on participants' image of Vancouver. Specifically, the You Gotta Be Here ad campaign run in conjunction with the Olympics featured Canadian celebrities and depicted Vancouver's downtown, beaches, parks, and wine and culinary attractions.

Given the short period of time post-Olympics during which the data in this study was gathered, it was surprising that image components directly related to the Olympics were not present. The results support more traditional studies of destination image, which argue that the overall image of a tourism destination does not change much over time, but the components of the image may change (Crompton, 1979; Gartner \& Hunt, 1987). Nevertheless, more recent studies dispute such reports, noting that the image of a destination and the image formation process is a dynamic process being influenced by a variety of agents (Baloglu \& McCleary, 1999, Choi, Lehto \&Morrison, 2007; Govers, Go \& Kumar, 2007). Therefore, it might be that the image of Vancouver as an Olympic host city has not been fully adopted by the Facebook participants because of Tourism Vancouver's decision to focus post-event promotional efforts on dining experiences, as opposed to Olympicrelated experiences and nostalgia.

Past research has shown that tourists revisit Olympic host-cities because of nostalgia or enhanced perceptions of the destination's image (Funk \& Bruun, 2007; Gibson et al., 2008; Gibson et al., 2002; Higham, 1999; Kaplanidou, 2007; Wilson, 2004). However, intentions to visit and revisit Vancouver seemed to be more related to the unique and common attributes of Vancouver such as the "wonderful", "Victoria", and the "downtown", than to the Olympics. The "Olympics", as a unique image component, was not related to intentions to revisit at all, and only marginally connected to intentions to visit. Intentions to "visit" were in the same cluster as the "Olympics" which could imply that the "Olympics" impact people's desires to visit Vancouver, however, intentions to "revisit" are mostly tied to the "menu" offerings and "wonderful" "Victoria." This finding suggests that intentions to revisit are not necessarily based on the Olympics, but rather on how "exciting" and "wonderful" Vancouver can be. Kaplanidou (2007), in her discussion of the 2004 Olympic Games in Athens, noted that "the event's image dimensions did not influence directly intentions to return to the destination. Potentially, the feelings Olympic travellers experienced about the event were confined in the boundaries of the event's organization and services and did not spill over to the image of Athens" (p. 170). Kaplanidou further argued that the overall image of the destination could mediate the impact of the Olympics' image on the destination image. To address this gap, event organizers and destination marketers could cooperate to promote post Olympic events.

A possible explanation for the disconnect between intentions to revisit and the Olympics, as well as for the lack of Olympic-related image descriptors, is the Dine Out celebration widely promoted on the DMO's Facebook Website. Both image clusters include words representative of this promotional effort. The findings of the current study indicate the relative importance of overt induced (Gartner, 1993) and stimulus image formation agents (Baloglu \& McCleary, 1999) such as Facebook. The abundance of food and restaurant-related image components illustrates how the image of a destination can be impacted in a relatively short post-Olympics period. Govers, Go and Kumar (2007) argued that decision makers should attempt to capitalize on temporal environmental and situational influences such as the Olympics. If DMOs want to capitalize on the Olympics as an image formation agent, they must direct their promotional efforts to influence the adoption of Olympic related perceptions and impressions.

Moreover, the present investigation has implications for data collection methods used in assessing destination images. So far, 
researchers have focused on a number of online websites to gather tourists' impressions and perceptions of various destinations (Choi, et al, 2007; Stepchenkova and Morrison, 2008; Tang et al, 2009). However, the comments left by thousands of Facebook fans have not been used to examine destination images in the context of a post-Olympic host city. Although it has become relatively common for destination marketing organizations to promote their tourism products on Facebook, research on such social media sites is still not widely adopted. This trend might stem from rather superficial, short answers often posted on such sites, as well as the need to sift through and summarize extremely large amounts of textual data. Nevertheless, qualitative computer software programs such as CATPAC II could be used by destination marketers to analyze large amounts of text in a short period of time. Additionally, the CATPAC II program can provide marketers with up-to-date information about tourists' discussions of tourism products, as well as positive and negative evaluations of the destination. These data, in turn, can inform the development of effective marketing strategies.

Lastly, the study does have some limitations. First, content analysis is an exploratory research method which relies on the interpretation and judgements made by the researchers. The image components clusters that emerged from CATPAC provide some insight into the co-occurrence of words in the text. However, interpretation of the meanings associated with the co-occurrence of words is subjective and based on the researchers' understanding of the text and the context in which the Facebook comments were written.

As well, our analysis is valid only in terms of the time frame of the investigation. In other words, Facebook users' image components and intention to visit and revisit Vancouver may have altered since completing the investigation. However, this study demonstrated that destination images and intentions to revisit can be captured at any point in time by a destination marketer or researcher who wishes to use on-line social networking sites such as Facebook. Indeed, this study provided "real time" data related to the images people held of Vancouver as an Olympic-host city.

\section{Conclusion}

The purpose of this study was to examine postevent destination image components of Vancouver, British Columbia, as expressed by Facebook users on Tourism Vancouver's official Facebook page. Two image component clusters emerged. The first cluster denotes images related to summer vacations, walks with children in wonderful Victoria and being excited about the delicious menu offerings. On the other hand, the second cluster portrays image components related to the main attractions in Vancouver such as the Granville Island, the Olympic festival, and the "cool" downtown which can be visited during a weekend night. Thus, the results demonstrate the multidimensionality of Vancouver's image as perceived by Facebook users: that of a relaxing destination yet full of excitement and "cool" attractions. Also, the use of Internet postings from Facebook can be limiting in that the participants selected might not be representative of the general tourist population. These Facebook members already have an invested interest and image of Vancouver as a tourist destination. That said, the sample should still be of interest to destination markets because they are likely a more responsive market segment compared to the general tourist population.

Findings of this study suggest that staging a mega event by itself will not influence destination image, unless proper marketing strategies are adopted. It is still possible that the Olympics might have inspired participants' perceptions of Vancouver as observed in the present investigation. Indeed, it is difficult to isolate Olympic elements and show their direct influence in image formation. Future studies should also address the pre-image components and compare them to post-image components to understand the influence of such megaevents on image formation. Lastly, this research was also aimed at showing that social media sites, such as Facebook, can be a substantial source of strategic information. Information gathered from social networking sites can be used by destination marketing organizations to discover what visitors have to 
say about their experiences, and to monitor their perceptions and impressions of the destination in "real time."

\section{References}

Alcaniz, E. B, Garcia, I. S. \& Blas, S. S. (2009). The functional-psychological continuum in the cognitive image of a destination: A confirmatory analysis. Tourism Management, 30, 715-723.

Baloglu, S. \& McClearly, K. W. (1999). A model of destination image formation. Annals of Tourism Research, 26(4), 868-897.

Banyai, M. (in press). Travel blogs: a reflection of positioning strategies? Journal of Hospitality Marketing \& Management, DOI: 10.1080/19368623.2012.624297

Buhalis, D., \& Law, R. (2008). Progress in information technology and tourism management: 20 years on and 10 years after the Internet - the state of eTourism research. Tourism Management, 29(4), 609-623.

Carson, D. (2008). The 'blogoshpere' as a market research tool for tourism destinations: A case study of Australia's Northern Territory. Journal of Vacation Marketing, 14, 111-119.

Chalip, L., Green, B. C., \& Hill, B. (2003). Effects of sport event media on destination image and intention to visit. Journal of Sport Management, 17, 214234.

Chen, C. \& Tsai, D. (2007). How destination image and evaluative factors affect behavioral intentions? Tourism Management, 28, 1115-1122.

Choi, S., Lehto, X. Y., \& Morrison, A. M. (2007). Destination image representation on the web: Content analysis of Macau travel related websites. Tourism Management, 28, 118-129.

Crompton, J. L. (1979). An assessment of the image of Mexico as a vacation destination and the influence of geographical location upon that image. Journal of Travel Research, 17(Spring), 18-23.

Crompton, J.L., \& Lee, S. (2000). The economic impact of 30 sports tournaments, festivals, and spectator events in seven U.S. cities. Journal of
Park and Recreation Administration, 18(2), 107-126.

Dimanche, F. (2003). The role of sport events in destination marketing. Paper presented at the AIEST 53rd Congress in Sport and Tourism, Athens, Greece.

Dıaz-Martın, A. M., Iglesias, V., Vazquez, R., \& Ruiz, A. V. (2000). The use of quality expectations to segment a service market. Journal of Services Marketing, 14(2), 132-146.

Echtner, C. M, \& Ritchie, J. R. B (1991). The meaning and measurement of destination image. The Journal of Tourism Studies, 2(2), 2-12.

Facebook (2012). Latest Statistics. URL: http://www.facebook.com/press/info.ph p?statistics (accessed on 20/10/2010)

Funk, D. C., \& Bruun, T. J. (2007). The role of socio-psychological and culturaleducation motives in marketing international sport tourism. A crosssectional perspective. Tourism Management, 28, 806-819.

Gartner, W. (1993) Image formation process. Journal of Travel and Tourism Marketing, 2(2/3), pp. 191-215.

Gartner, W. C., \& Hunt, J. D. (1987). An analysis of state image change over a twelve-year period (1971-1983). Journal of Travel Research, 26(Fall), 15-19.

Gibson, H. J., Willming, C., \& Holdnak, A. (2002). "We're Gators not just a Gator fan:" Serious Leisure, social identity, and University of Florida Football. Journal of Leisure Research, 14, 397425.

Gibson, H. J., Qi Xueqing, C., \& Zhang, J. J. (2008). Destination image and intent to visit China and the 2008 Beijing Olympic Games. Journal of Sport Management, 22(4), 427-450.

Govers, R. \& Go, F. M. (2005). Projected destination image online: Website content analysis of pictures and text. Information Technology \& Tourism, 7 , 73-89.

Govers, R., Go, F. M. \& Kumar, K. (2007). Promoting Tourism Destination Image. Journal of Travel Research, 46, 15-23. 
Gunn, C. (1988) Vacationscape: designing tourists regions. New York: Van Nostrand Reinhold.

Hall, C. M. (1989a). The definition and analysis of hallmark tourist events. Geojournal, 19(3), 263-268.

Higham, J. (1999). Sport as an avenue of tourism development: An analysis of the positive and negative impacts of sport tourism. Current Issues in Tourism, 2(1), 82-90.

Kaplanidou, K. (2007). Affective event and destination image: Their influence on Olympic Travelers' Behavioral intentions. Event Management, 10, 159-173.

Kaplanidou, K., \& Gibson, H. (2010). Predicting behavioral intentions of active event sport tourists: The case of a small scale recurring sports event. Journal of Sport \& Tourism, 15, 163-179.

Kaplanidou, K., \& Vogt, C. (2009). The theory of planned behavior, past experience, satisfaction, and event attendance during the post-even consumption phase. Abstracts from the 2009 International Conference on Festivals \& Events Research (ICFER). January 1821, Orlando, FL.

Kim, S., \& Morrison, A. (2005). Change of images of South Korea among foreign touristsafter the 2002 FIFA World Cup. Tourism Management, 26, 233-247.

Litvin, S. W., Blose, J. E., \& Laird, S. T. (2004). Tourist use of restaurant web-pages: Is the internet a critical marketing tool? Journal of Vacation Marketing, 11(2), 155-161.

Litvin, S. W, Goldsmith, R. E. \& Pan, B. (2008). Electronic word-of-mouth in hospitality and tourism management. Tourism Management, 29, 458-468.

MacKay, K. J., \& Fesenmaier, D. R. (1997). Pictorial element of destination in image formation. Annals of Tourism Research, 24, 537-565.

Morgan, N. J., Pritchard, A., \& Piggott, R. (2003). Destination branding and the role of the stakeholders: The case of New Zealand. Journal of Vacation Marketing, 9(3), 285-299.

O'Neill, M., Palmer, A., \& Charters, S. (2002). Wine production as service
experience-The effects of service quality on wine sales. The Journal of Services Marketing, 16(4), 342-362.

Pan, B., MacLaurin, T. \& Crotts, J.C. (2007) Travel blogs and the implications for destination marketing. Journal of Travel Research, 46, 35-46.

Pike, S. (2002). Destination image analysis: A review of 142 papers from 1973 to 2000. Tourism Management, 23, 541549.

Ritchie, J. R. B., \& Smith, B. (1991). The impact of a mega-event on host region awareness: A longitudinal study. Journal of Travel Research, 30(1), 310.

Ryan, C. \& Cave, J. (2005). Structuring destination image: a qualitative approach. Journal of Travel Research, 44, 143-150.

San Martin, H. \& del Bosque, I.A. (2008). Exploring the cognitive-affective nature of destination image and the role of psychological factors in its formation. Tourism Management, 29, 263-277.

Schmallegger, D. \& Carson, D. (2007). Blogs in tourism: Changing approaches to information exchange. Journal of Vacation Marketing. 14(2), 99-110.

Shonk, J. D., \& Chelladurai, P. (2008). Service quality, satisfaction, and intent to return in event sport tourism. Journal of Sport Management, 22(5), 587-602.

Stepchenkova, S. \& Morrison, A. M. (2006). The destination image of Russia: From the online induced perspective. Tourism Management, 27, 943-956.

Stepchenkova, S. \& Morrison, A. M. (2008). Russia's destination image among American pleasure travelers: Revisit Echtner and Ritchie. Tourism Management, 29, 548-560.

Tasci, A. D. A., \& Gartner, W. C. (2007). Destination image and its functional relationships. Journal of Travel Research, 45(4), 413-425.

Tasci, A. D. A., Gartner, W. C. \& Cavusgil, S. T. (2007). Conceptualization and operationalization of destination image. Journal of Hospitality \& Tourism Research, 31(2), 194-223.

Tang, L., Choi, S., Morrison, A.M. \& Lehto, X. Y. (2009). The many faces of Macau: A 
Assessing destination images of an Olympic host city using social media.

correspondence analysis of the images communicated by online tourism information sources in English and Chinese. Journal of Vacation Marketing, 15(1), 79-94.

Waitt, G. (2003). Social impacts of the Sydney Olympics. Annals of Tourism Research, 30(1), 194-215.

Wenger, A. (2008). Analysis of travel bloggers' characteristics and their communication about Austria as a tourism destination. Journal of Vacation Marketing, 14, 169-176.

Wilson, A. (2004). The relationship between consumer role satisfaction and nostalgia sport tourism:
A symbolic interactionist perspective. Unpublished master's thesis, University of Florida, Gainesville.

Woelfel, J. (1993). Artificial neural networks in policy research: A current assessment. Journal of Communication, 43(1), 6380.

Woelfel, J. (1998). User's guide: Captac II Version 2.0. Rah Press.

Xiang, Z. \& Gretzel, U. (2010). Role of social media in online travel information search. Tourism Management, 31, 179188. 